\title{
Elevated distress among patients undergoing screening for lung cancer
}

\author{
April Plank ${ }^{1}$, Barbara Nemesure ${ }^{* 2}$ \\ ${ }^{1}$ Department of Radiology, Stony Brook Medicine, United States \\ ${ }^{2}$ Department of Family, Population and Preventive Medicine, Stony Brook Medicine, United States
}

Received: October 5, 2015

DOI: $10.5430 /$ jnep.v6n4p65
Accepted: December 10, $2015 \quad$ Online Published: December 16, 2015

URL: http://dx.doi.org/10.5430/jnep.v6n4p65

\begin{abstract}
Objective: Low-dose CT scanning has recently been recommended to screen patients at elevated risk of developing lung cancer, however, limited data exist describing distress experienced by this at-risk population. The objective of this study is to describe the prevalence and risk factors of high distress among patients undergoing screening for lung cancer.

Methods: The validated National Comprehensive Cancer Network Distress Thermometer (DT) was used to evaluate distress prior to and following lung cancer screening among 228 patients attending the Center for Lung Cancer Screening and Prevention at the Stony Brook Cancer Center between September 30, 2013 and September 29, 2014. Clinically significant distress was defined by a score $\geq 4$ on the DT instrument and logistic regression models were used to evaluate factors associated with high distress.

Results: Forty-three percent of study participants experienced elevated distress prior to screening, while approximately one-third of patients reported distress scores $\geq 4$ post-screening. Risk factors for elevated distress before screening included female gender $(\mathrm{OR}=2.68 ; 95 \% \mathrm{CI}[1.51,4.77])$ and having a positive family history of lung cancer $(\mathrm{OR}=2.02[1.04,3.91])$, while significant associations with post-screening distress were found among females $(\mathrm{OR}=3.16[1.73,5.80])$, current smokers $(1.85[1.00,3.42])$ and those with a positive personal history of a non-cancerous lung diagnosis $(\mathrm{OR}=1.87[1.00,3.51])$.

Conclusions: The lung cancer screening population is a vulnerable group burdened by increased levels of distress. The screening visit represents a unique opportunity to not only educate patients about lung health and smoking cessation but additionally to address issues related to psychological wellness.
\end{abstract}

Key Words: Lung cancer, Screening, Distress, Distress Thermometer

\section{INTRODUCTION}

Low dose computed tomography (LDCT) scanning is recommended by the United States Preventive Services Task Force (USPSTF) for screening patients at increased risk for developing lung cancer. ${ }^{[1]}$ It is estimated that 8.6 million adults in the United States meet the USPSTF screening criteria based primarily on age and a history of heavy tobacco use. ${ }^{[2]}$ Although a strong evidence base provided by the National Lung Screening Trial (NLST) ${ }^{[3]}$ and others ${ }^{[4-7]}$ has demonstrated the utility and efficacy of LDCT for the early detection of lung cancer among high-risk patients, limited data are available describing the prevalence of distress in the lung cancer screening population. ${ }^{[8-13]}$ Two reports have described issues relating to the impact of lung cancer screening on health-related quality of life ${ }^{[8,13]}$ however, the level of distress experienced by lung cancer screening patients has not been well established.

The cohort eligible for lung cancer screening represents an at-risk group being screened for the deadliest cancer type

\footnotetext{
* Correspondence: Barbara Nemesure; Email: Barbara.Nemesure@stonybrookmedicine.edu; Address: Department of Family, Population and Preventive Medicine, Stony Brook Medicine, United States.
} 
and $90 \%$ of cases have voluntarily and consciously made the decision to engage in a known destructive behavior (tobacco use) over a long period of time. These factors are likely to influence levels of anxiety and stress and may negatively impact quality of life in this high-risk population. The magnitude and potential consequences of psychological sequela that may already be presented in this vulnerable group or may become manifest as a result of the lung cancer screening process remains unknown. The purpose of this investigation is to quantify the degree of distress experienced by lung cancer screening patients before and after screening and to evaluate risk factors and implications of such distress.

\section{Methods}

The present investigation is based on 228 lung cancer screening patients attending the Center for Lung Cancer Screening and Prevention (CLCSP) at the Stony Brook Cancer Center between September 30, 2013 and September 29, 2014. Stony Brook is located in Suffolk County, New York with an estimated population of 1.5 million of which $18 \%$ of adults are current smokers. The protocols for the present investigation were reviewed and approved by the Stony Brook University Institutional Review Board (IRB) and informed consent was obtained from all study participants.

\subsection{Eligibility criteria}

The CLCSP follows the National Comprehensive Cancer Network (NCCN) eligibility guidelines for lung cancer screening which include individuals 55 years of age or older with a 30 pack-year history of tobacco use and smoking cessation $<15$ years or those $\geq 50$ years of age with $\geq 20$ pack year history of tobacco use and one additional risk factor (family history of lung cancer, history of other cancer, history of lung disease or history of exposure to lung carcinogens such as asbestos, silica, radon, 911 exposure, etc. $)^{[14]}$ Eligible study participants were required to meet the NCCN lung cancer screening criteria and additionally provide both preand post-screening distress scoring information during the screening visit.

\subsection{Data collection instruments}

A brief study survey was administered to all consented screening participants. The questionnaire included items related to demographics (e.g., age, gender, smoking status), medical history (e.g., history of asthma, COPD, emphysema, and other lung-related diagnoses) and family history of lung cancer. In addition to the study questionnaire, levels of distress at the start and conclusion of the lung cancer screening visit were obtained using the NCCN Distress Thermometer (DT), a validated visual analog tool based on an ordinal rating scale from 0 (no distress) to 10 (extreme distress). ${ }^{[15]}$ The DT instrument also includes a section designed to capture those factors influencing the distress score. The categories are subdivided as follows: practical problems (child care, housing, insurance/financial, etc.), family problems (dealing with children, partner, family health issues, emotional problems (nervousness, worry, depression, etc.), spiritual/religious concerns and physical problems (pain, fatigue, breathing, etc.). The NCCN DT measure is often referred to as the "6th vital sign" and is part of routine intake at the Stony Brook Cancer Center. A DT score of 4 or higher is indicative of a clinically significant level of distress. ${ }^{[15]}$

\subsection{Study visit}

Patients were initially screened to ensure eligibility. Once confirmed, patients received a low-dose chest CT scan. The screening visit included the completion of the NCCN DT instrument and a brief study survey at the start of the visit, followed by a complete history and physical, provision of the CT scan screening results, and noted recommendations provided by the Center's nurse practitioner. All patients were engaged in conversation regarding reported distress levels. Resources regarding distress management were provided when appropriate and referrals for additional consults were completed as needed. Current smokers were additionally offered tobacco cessation counseling.

At the conclusion of the visit, after receiving the screening results and speaking with the nurse practitioner, patients were asked to complete the post-screening DT instrument once again. The complete visit generally spanned 30-45 minutes.

\subsection{Statistical analyses}

Descriptive statistics were used to describe the demographic and other characteristics of the study population. Since the DT tool is based on an ordinal scale from 0 (no distress) to 10 (extreme distress) and a score of 4 or higher is considered clinically significant, prevalence of high distress was determined as the proportion of those patients reporting a score $\geq 4$. Chi-squared tests were used to evaluate univariate factors potentially related to high distress $(\geq 4 v s .<4)$ prior to and following screening and $p$-values $\leq .05$ were taken to indicate statistically significant findings. Logistic regression analyses to evaluate associations between potential risk factors and elevated distress included age, gender, smoking status, family history of a first degree relative and a personal history of non-cancerous lung diagnoses. For the purposes of this investigation, we define first-degree relatives as parents and siblings of the participant.

Odds ratios and $95 \%$ confidence intervals are reported. Data were analyzed using SPSS version 21. 


\section{Results}

The distribution of demographic characteristics for 228 patients meeting the study's eligibility criteria, as described above, is presented in Table 1. The average (standard deviation) age of the patients was 61.3 (6.7) years and approximately $60 \%$ of those screened were male. $43 \%$ of patients were current smokers and approximately one-quarter reported a family history of lung cancer in a first degree relative. About one-third of the study sample also had a prior (personal) history of a non-cancerous lung diagnosis.

A total of $43.4 \%$ of lung cancer screening patients reported a distress score of greater than or equal to 4 before screening and $31.1 \%$ reported a score of 4 or higher at the end of the study visit, despite receipt of a non-cancerous diagnosis. Severe distress (DT score $\geq 7$ ) was noted among $24.1 \%$ and $6.1 \%$ of patients before and after screening, respectively. Factors included on the DT instrument that were predominantly reported as contributing to elevated distress were emotional (worry, nervousness, etc.) and practical (caretaking, etc.) in nature, particularly among women.

Level of distress generally remained the same $(52.6 \%)$ or decreased $(40.4 \%)$ between the pre- and post-screening evaluations in the majority of study participants, however, $\mathrm{n}=$ 16 (7\%) patients reported higher distress scores at the conclusion of the screening visit. These reported increases were not related to a cancer diagnosis nor clinically concerning CT finding.

Table 2 provides the distribution of high distress (DT score $\geq 4$ ) for demographic and other characteristics among study participants both prior to and post-screening. Females reported elevated distress scores significantly more often than males both before $(p<.01)$ and after $(p<.01)$ being screened for lung cancer. Current smokers tended to report higher distress scores than former smokers. At the conclusion of the screening visit $40.5 \%$ of current smokers and $24.0 \%$ of former smokers reported DT scores $\geq 4(p=.02)$. Elevated distress levels were also reported more frequently among those with a positive family history of lung cancer $(p=.03)$, however, these findings only achieved statistical significance at the start of the visit. A history of other (non-cancerous) lung disease was associated with distress at the conclusion of the visit $(p=.02)$.

Table 1. Demographic characteristics of high risk lung cancer screening patients $(\mathrm{N}=228)$

\begin{tabular}{ll}
\hline Characteristics & \\
\hline Age, years (mean \pm SD) & $61.3 \pm 6.7$ \\
Gender & \\
Male & $60.1 \%$ \\
$\quad$ Female & $39.9 \%$ \\
Smoking Status & \\
$\quad$ Former smoker & $56.6 \%$ \\
$\quad$ Current smoker & $43.4 \%$ \\
Family History of Lung Cancer & \\
$\quad$ Parent & $19.9 \%$ \\
Sibling & $6.1 \%$ \\
$\quad$ Any first degree relative* & $24.0 \%$ \\
History of Other Lung Diagnosis** & $32.5 \%$ \\
\hline
\end{tabular}

*parent or sibling; **asthma, copd, idiopathic pulmonary fibrosis, spontaneous pneumothorax, chest trauma, emphysema

Table 2. Univariate analyses to evaluate factors related to elevated distress before and after screening among high risk lung cancer screening patients $(\mathrm{N}=228)$

\begin{tabular}{|c|c|c|c|c|}
\hline \multirow{3}{*}{ Characteristics } & \multicolumn{4}{|c|}{ Elevated Distress Level } \\
\hline & \multicolumn{2}{|c|}{ Prior to Screening } & \multicolumn{2}{|l|}{ Post Screening } \\
\hline & \% With Score $\geq 4$ & $p$-value & $\%$ With Score $\geq 4$ & $p$-value \\
\hline \multicolumn{5}{|l|}{ Gender } \\
\hline Male & $33.6 \%$ & $<.01$ & $20.4 \%$ & $<.01$ \\
\hline Female & $58.2 \%$ & & $47.3 \%$ & \\
\hline \multicolumn{5}{|l|}{ Smoking Status } \\
\hline Former smoker & $38.0 \%$ & .06 & $24.0 \%$ & .01 \\
\hline Current smoker & $50.5 \%$ & & $40.5 \%$ & \\
\hline \multicolumn{5}{|l|}{ Age } \\
\hline $\mathrm{Age}<60$ years & $51.0 \%$ & .04 & $30.8 \%$ & .99 \\
\hline $\mathrm{Age} \geq 60$ years & $37.1 \%$ & & $31.5 \%$ & \\
\hline \multicolumn{5}{|c|}{ Family History of Lung Cancer* } \\
\hline Yes & $58.5 \%$ & .02 & $34.0 \%$ & .74 \\
\hline No & $39.3 \%$ & & $31.0 \%$ & \\
\hline \multicolumn{5}{|c|}{ History of Other Lung Diagnosis } \\
\hline Yes & $47.3 \%$ & .48 & $41.9 \%$ & .02 \\
\hline No & $41.6 \%$ & & $26.0 \%$ & \\
\hline
\end{tabular}

*In first degree relative 
Table 3 presents the results of the logistic regression analyses to evaluate factors potentially related to elevated distress before and after lung cancer screening. Female gender represented the strongest risk factor for increased distress both prior to and following screening $(\mathrm{OR}=2.68[1.51,4.77]$ before screening; $\mathrm{OR}=3.16[1.73,5.80]$ after screening). At the pre-screening visit, a positive family history of lung cancer was found to be associated with elevated distress (OR $=2.02[1.04,3.91])$, while having a positive personal history of a non-cancerous lung diagnosis was a significant risk factor for high distress at the end of the screening visit (OR = $1.87[1.00,3.51])$. Current smokers were also significantly more likely to report DT scores $\geq 4$ at the end of the visit compared to former smokers.

Table 3. Logistic regression analyses to evaluate factors related to elevated distress before and after screening among high risk lung cancer screening patients $(\mathrm{N}=228)$

\begin{tabular}{lll}
\hline \multirow{2}{*}{ Factors } & \multicolumn{2}{l}{ Elevated Distress (Score $\geq 4)$} \\
\cline { 2 - 3 } & \multicolumn{1}{l}{ Prior to Screening } & Post Screening \\
\cline { 2 - 3 } & OR $(\mathbf{9 5 \%}$ CI) & $3.16(1.73,5.80)^{*}$ \\
\hline Gender (female) & $2.68(1.51,4.77)^{*}$ & $0.95(0.51,1.76)$ \\
Age (younger) & $1.75(0.98,3.11)$ & $1.85(1.00,3.42)^{*}$ \\
Smoking status (current) & $1.61(0.90,2.86)$ & $0.99(0.48,2.02)$ \\
Positive family history of lung cancer in first degree relative & $2.02(1.04,3.91)^{*}$ & $1.87(1.00,3.51)^{*}$ \\
Positive personal history of lung diagnosis & $0.97(0.52,1.79)$ & OR \\
\hline
\end{tabular}
${ }^{*} p \leq .05$

\section{Discussion}

This study provides important new data regarding distress experienced by a high-risk population undergoing screening for lung cancer. The findings indicate that clinically significant levels of distress are present in more than $40 \%$ of the screening population just prior to the initial visit and are maintained by approximately one-third of patients post-screening, despite receiving a non-cancerous diagnosis. Women and current smokers tended to report higher levels of distress in this study and such distress may have negative implications with respect to smoking cessation and overall quality of life. Lung cancer screening is a relatively new recommendation and provides a unique and valuable opportunity for the development of patient education initiatives and clinical pipelines to identify and address the psychological sequela experienced by this vulnerable population.

There is an abundance of evidence describing the presence of distress among patients diagnosed and treated for cancer. ${ }^{[15-19]}$ While elevated levels of stress and anxiety are common among cancer patients in general, levels of distress among those with lung cancer are nearly always higher than all other cancer sites. ${ }^{[20,21]}$ In a study by Zabora et al. including over 4,400 patients comparing 14 different cancer sites, the prevalence of distress was found to be highest among lung cancer patients (43.4\%). This study showed significant variation in the prevalence of distress with the lowest rate reported among women with gynecological cancer (29.6\%). ${ }^{[21]}$ Many experts agree that these findings may be partially explained by the guilt that is often associated with lung cancer and its direct relation to smoking. ${ }^{[22]}$

Only a limited number of studies to date, however, have reported on the presence of psychological factors in a high-risk lung cancer screening population. ${ }^{[8,23]}$ Of these, the main focus has been predominantly on stress related to awaiting results ${ }^{[23]}$ and/or the anxiety associated with the presence of indeterminate findings. ${ }^{[3,8,9]}$ Byrne et al. evaluated the psychological impact of lung cancer screening in 400 patients using surveys collected before and after screening, at 6 and 12 months. The study data included demographic information, state/trait anxiety, fear of cancer and perceived risk of lung cancer. Findings indicated that those who received indeterminate or suspicious screening results had negative psychological effects. ${ }^{[9]}$ In a second study, Vierkko $e t$ al. investigated the psychological impact of screening for both lung cancer and pulmonary disease among 633 asbestos workers. Elevated anxiety was reported in the cohort during the screening process but decreased after negative findings were provided. There were no long term negative effects noted in this study population. ${ }^{[11]}$

The NLST is the largest randomized controlled trial to date designed to evaluate the use of low dose chest CT scan compared to chest $\mathrm{X}$-ray in patients at risk for lung cancer. ${ }^{[3]}$ Psychological data from the NLST were collected among 2,812 of the nearly 54,000 patients enrolled. Patients found to have significant clinical findings or false positive results from their screening visit did not report that such findings impacted their health related quality of life (HRQoL) or anxiety 
scores at 1 month and 6 months post screening. ${ }^{[13]}$ There are no data currently available from this trial relating to distress in this population and its impact on adherence to screening.

While data relating to distress and lung cancer screening is relatively limited, a review of the literature, including screening of other cancer sites, indicates that anxiety is a common theme with elevated levels being well-documented among patients undergoing screening for breast and colon cancers. ${ }^{[24-27]}$ These findings, however, generally indicate that minimal to moderate levels are reported during the screening process but subsequently decrease upon receipt of a non-cancerous finding. ${ }^{[24-27]}$ Similar to other cancer types, participants in the present study experienced moderate levels of distress prior to being screened for lung cancer. However, unlike the published reports for breast and colon cancers, elevated distress scores were maintained among approximately $1 / 3$ of the study's lung cancer screening patients, despite receipt of a non-concerning finding.

While screening protocols for other cancer types are typically targeted to the general population, lung cancer screening is directed towards a unique "high-risk" cohort with a history of significant tobacco use. This addictive behavior, either current or past, has been shown to result in higher frequencies of behavioral and psychological consequences, as well as increased distress. ${ }^{[28,29]}$ As such, elevated levels of distress demonstrated in the high-risk lung cancer screening population may be exacerbated by the cognizance of participating in negative behaviors that precipitated lung cancer screening in the first place. Additionally the heightened feelings of distress may be a consequence of the guilt associated with a significant history of tobacco use, fear of subsequent smoking-induced implications or a variety of other related factors.

Although moderate levels of distress are to be expected among individuals being screened for cancer, elevated levels after the provision of a non-concerning finding among lung cancer screening patients represents a concern with multifaceted ramifications. The consequences of such distress burdens the individual in particular and the health care system at large, and may have significant clinical, economic and quality of life implications. Additionally, the presence of such increased distress may impact future screening compliance, as well as readiness to quit and tobacco cessation efforts in this high-risk group. Lung cancer screening programs provide unique opportunities to: 1) address underlying psychological issues which may serve as barriers to care or negatively impact quality of life and 2) serve as "teachable moments" to provide patient education regarding smoking cessation and overall lung health.
This study has several limitations. The sample size was moderate and the data may not be generalizable to the general lung cancer screening population. Additionally, the NCCN DT instrument was not designed to assess distress among screening patients but rather developed for use among cancer patients during the diagnosis and treatment phases of cancer care. Despite these given limitations, the findings appear compelling enough to begin considering the need to address the noted increased levels of distress experienced by patients being screened for lung cancer. These individuals may require further clinical care and would likely benefit from additional educational initiatives.

Of final note, it is possible that smoking cessation counseling provided during the clinic visit may have impacted post-visit distress scores, however this study was unable to differentially quantify the impact of such counsel on the level of distress attributed to screening itself, as opposed to other factors. The study did, however, collect pre- and post- screening data that provide a broad indication of intra-patient distress potentially related to the screening process. These data indicate that distress level remained unchanged in about half of the patients and decreased in approximately $40 \%$ of patents following receipt of their lung cancer screening findings. This implies that some level of distress may be attributable to screening itself in at least two-fifths of patients, which is not an unexpected finding. However, more concerning are the generally elevated levels of sustained distress experienced by this cohort.

It is essential to begin to raise awareness regarding the presence of transient, as well as chronic, elevated distress experienced by those being screened for lung cancer. Data from the present study indicate that more than $40 \%$ of screening patients are current smokers and these individuals report significantly higher distress scores than former smokers. Since tobacco use is the single most important modifiable risk factor for lung cancer and there is some evidence that distress may impact one's ability to quit smoking, ${ }^{[30]}$ it is important to recognize and address major obstacles potentially inhibiting patient willingness to engage in a smoking cessation effort. Although many new programs are feverishly working to establish the necessary infrastructures to provide LDCT scans for their at-risk lung cancer screening patients, it is imperative that awareness is not lost on an equally important (and often overlooked) factor-the patients' psychological well-being (before, during and after the screening process). Although the distress of being screened for lung cancer is not likely to fully account for a patient's intrinsic distress, lung cancer screening programs present ripe opportunities for patient education in this vulnerable population. Capitalizing on these teachable moments and providing referrals for 
appropriate clinical care may help to improve overall patient health and well-being.

\section{Conclusions}

Early detection remains the most hopeful avenue for improving cancer-related health outcomes. Our data suggest the need to recognize the presence and role that distress may play as a potential barrier to the lung cancer screening effort and to develop strategies, support mechanisms and education initiatives to address the notable levels of elevated distress experienced by this vulnerable group. Additional research is necessary to better understand the impact of such distress in the high-risk lung cancer screening population. The Center for Lung Cancer Screening and Prevention at the Stony Brook Cancer Center continues to investigate the relationship between distress and lung cancer screening so that programs can be expeditiously developed and refined to address the unique and significant needs required by this group.

\section{CONFLiCTS OF INTEREST Disclosure}

The authors declare that they have no conflict of interest.

\section{REFERENCES}

[1] Moyer VA, Force USPST. Screening for lung cancer: U.S. Preventive Services Task Force recommendation statement. Annals of internal medicine. 2014; 160(5): 330-8. PMid:24378917 http: //dx.doi.org/10.7326/M13-2771

[2] Healio. Heme Onc Today 10 fast facts about the USPSTF lung cancer screening guidelines. 2014. Available from: http://www.healio.com/hematology-oncology/practice -management/news/online/\%7B9d533f08-0a18-4002-858 6-9ebdf 651 afb0\%7D/10-fast-facts-about-the-uspstf-1 ung-cancer-screening-guidelines

[3] National Lung Screening Trial Research team, et al. Reduced lung-cancer mortality with low-dose computed tomographic screening. The New England Journal of Medicine. 2011; 365(5): 395409. PMid:21714641 http://dx. doi .org/10.1056/NEJMoa110 2873

[4] Pedersen JH, Ashraf H, Dirksen A, et al. The Danish randomized lung cancer CT screening trial-overall design and results of the prevalence round. Journal of thoracic oncology. Official publication of the International Association for the Study of Lung Cancer. 2009; 4(5): 608-14.

[5] van Klaveren RJ. Lung cancer screening with low dose computed tomography: Where do we stand today? European journal of cancer 2009; 45(Suppl 1): 375-6. http://dx.doi.org/10.1016/S0959 -8049 (09) $70054-1$

[6] Lopes Pegna A, Picozzi G, Mascalchi M, et al. Design, recruitment and baseline results of the ITALUNG trial for lung cancer screening with low-dose CT. Lung Cancer. 2009; 64(1): 34-40. PMid:18723240 http://dx.doi.org/10.1016/j.lungcan.2008.07.003

[7] Infante M, Cavuto S, Lutman FR, et al. A randomized study of lung cancer screening with spiral computed tomography: Threeyear results from the DANTE trial. American Journal of Respiratory and Critical Care Medicine. 2009; 180(5): 445-53. PMid:19520905 http://dx.doi.org/10.1164/rccm.200901-00760C

[8] van den Bergh KA, Essink-Bot ML, Borsboom GJ, et al. Shortterm health-related quality of life consequences in a lung cancer CT screening trial (NELSON). British Journal of Cancer. 2010; 102(1): 27-34. PMid:19935789 http://dx.doi.org/10.1038/sj.bjc. 6605459

[9] Byrne MM, Weissfeld J, Roberts MS. Anxiety, fear of cancer, and perceived risk of cancer following lung cancer screening. Medical Decision Making. 2008; 28(6): 917-25. PMid:18725404 http: //dx.doi.org/10.1177/0272989x08322013
[10] Bunge EM, van den Bergh KA, Essink-Bot ML, et al. High affective risk perception is associated with more lung cancer-specific distress in CT screening for lung cancer. Lung Cancer. 2008; 62(3): 38590. PMid:18468717 http://dx.doi.org/10.1016/j.lungcan .2008 .03 .029

[11] Vierikko T, Kivisto S, Jarvenpaa R, et al. Psychological impact of computed tomography screening for lung cancer and occupational pulmonary disease among asbestos-exposed workers. European Journal of Cancer Prevention. 2009; 18(3): 203-6. http: //dx.doi.org/10.1097/CEJ.0b013e328329d800

[12] Aggestrup LM, Hestbech MS, Siersma V, et al. Psychosocial consequences of allocation to lung cancer screening: A randomised controlled trial. 2012. e000663 p.

[13] Gareen IF, Duan F, Greco EM, et al. Impact of lung cancer screening results on participant health-related quality of life and state anxiety in the National Lung Screening Trial. Cancer. 2014; 120(21): 3401-9. PMid:25065710 http://dx.doi.org/10.1002/cncr. 28833

[14] NCCN. NCCN Guidelines. 2015. Available from: http//www.nc cn.org/patients/resources/life_with_cancer/pdf

[15] Graves KD, Arnold SM, Love CL, et al. Distress screening in a multidisciplinary lung cancer clinic: Prevalence and predictors of clinically significant distress. Lung Cancer. 2007; 55(2): 215 24. PMid:17084483 http://dx.doi.org/10.1016/j.lungcan .2006 .10 .001

[16] Mahon SM, Cella DF, Donovan MI. Psychosocial adjustment to recurrent cancer. Oncology Nursing Forum. 1990; 17(3 Suppl): 47-52. PMid:2342982

[17] Power J, Brown L, Ritvo P. A qualitative study examining psychosocial distress, coping, and social support across the stages and phases of epithelial ovarian cancer. Health Care for Women International. 2008; 29(4): 366-83. PMid:18389433 http://dx.doi.org/10. 1080/07399330701876521

[18] Norton TR, Manne SL, Rubin S, et al. Prevalence and predictors of psychological distress among women with ovarian cancer. Journal of Clinical Oncology. 2004; 22(5): 919-26. PMid:14990648 http://dx.doi.org/10.1200/JC0.2004.07.028

[19] Herschbach P, Keller M, Knight L, et al. Psychological problems of cancer patients: a cancer distress screening with a cancerspecific questionnaire. British Journal of Cancer. 2004; 91(3): 504 11. PMid:15238979 http://dx.doi.org/10.1038/sj.bjc.66 01986

[20] Cooley ME, Short TH, Moriarty HJ. Symptom prevalence, distress, and change over time in adults receiving treatment for lung 
cancer. Psycho-oncology. 2003; 12(7): 694-708. PMid:14502594 http://dx.doi.org/10.1002/pon.694

[21] Zabora J, BrintzenhofeSzoc K, Curbow B, et al. The prevalence of psychological distress by cancer site. Psycho-oncology. 2001; 10(1): 19-28. http://dx.doi.org/10.1002/1099-1611(200101/02) $10: 1<19:$ : AID-PON501>3.0.CO;2-6

[22] Chapple A, Ziebland S, McPherson A. Stigma, shame, and blame experienced by patients with lung cancer: qualitative study. BMJ. 2004; 328(7454): 1470. PMid:15194599 http://dx.doi.org/10. $1136 / \mathrm{bmj} .38111 .639734 .7 \mathrm{C}$

[23] Bach PB, Mirkin JN, Oliver TK, et al. Benefits and harms of CT screening for lung cancer: A systematic review. JAMA. 2012; 307(22): 2418-29. PMid:22610500 http://dx.doi.org/10.10 $01 /$ jama. 2012.5521

[24] Edgar L, Glackin M, Hughes C, et al. Factors influencing participation in breast cancer screening. British Journal of Nursing. 2013; 22(17): 1021-6. PMid:24067312 http://dx.doi.org/10.1296 8/bjon.2013.22.17.1021

[25] Consedine NS. A false-positive on screening mammography has a negative psychosocial impact up to 3 years after receiving the all clear. Evidence-based Mental Health. 2013; 16(4): 115. PMid:23852830 http://dx.doi.org/10.1136/eb-2013-101410
[26] Bond M, Pavey T, Welch K, et al. Systematic review of the psychological consequences of false-positive screening mammograms. Health technology assessment. 2013; 17(13): 1-170. http://dx.d oi.org/10.3310/hta17130

[27] Miles A, Wardle J. Adverse psychological outcomes in colorectal cancer screening: Does health anxiety play a role? Behaviour Research and Therapy. 2006; 44(8): 1117-27. PMid:16243291 http://dx.doi.org/10.1016/j.brat.2005.08.011

[28] Norris TF E-AM. Recent substance abuse and high levels of psychological distress among secondary school students in New South Wales. NSW Public Health Bulletin. 2008; 18: 7-8.

[29] Report SAaMhS. The NDSUH Report: Smoking and mental illness 2013. Available from: http://www.samhsa.gov/data/sites/ default/files/NSDUH093/NSDUH093/sr093-smoking-men tal-illness.pdf

[30] Cosci F, Pistelli F, Lazzarini N, et al. Nicotine dependence and psychological distress: Outcomes and clinical implications in smoking cessation. Psychology Research and Behavior Management. 2011; 4: 119-28. PMid:22114542 http://dx.doi .org/10.2147/PRBM. S14243 